\title{
Beets Go Mainstream
}

\section{Gary D Miller*}

Department of Health and Exercise Science, Wake Forest University, Winston-Salem, NC 27109 USA

The health benefits for consuming fruits and vegetables, as seen with the DASH (Dietary Approaches to Stop Hypertension) diet, have generated significant interest over the years, especially in certain sectors of the population looking for alternative approaches to conventional medical treatment. Large scale longitudinal observational studies exhibited the associations between fruit and vegetable intake and reductions in risk for cardiovascular disease [1-5]. While these benefits were initially linked with the rich source of micronutrients - vitamins and minerals - found in these foods, subsequent studies utilizing supplements with these nutrients failed to provide the same effect as intake of the foods [6]. Other phytochemicals have been investigated with mixed results. Currently, a chemical found in many of our vegetables that has stirred considerable interest in treating a variety of diseases associated with poor vascular health is nitrate.

Yes, this is the same food component that has been black-listed for its potential lead with gastric cancer and methemoglobinemia (i.e. blue baby syndrome). Nitrate is found in a variety of foods, but vegetables comprise $\sim 80 \%$ of our daily intake [7]. There is a large variation in the median concentration of nitrate in different vegetables (from 1 to 4800 $\mathrm{mg}$ nitrate/kg fresh weight) with highest levels in green leafy vegetables. A daily intake of $100 \mathrm{~g}$ of vegetables from a variety of sources provides about $250 \mathrm{mg}$ nitrate. One food that has garnered noteworthy attention as a nitrate source is beetroot, particularly the juice. A simple internet search demonstrates this popularity as there are dozens of companies now marketing a product high in beetroot. Although not all these companies promote nitrate in their advertising and health claims, the vast majority point towards the health benefits reported by its nitrate content. Beetroot juice has more than $12 \times$ the nitrate content than other vegetable juices. Albeit beetroot juice is not the food with the highest nitrate content, it has advanced the fastest in touting its health benefits. Other vegetables that have very high levels of nitrate $(>2500$ mg nitrate/kg fresh weight) include kale, celery, cress, chevil, Lamb's and Butterhead lettuce, spinach, and rucola. In contrast, processed meats such as bacon, ham, and hot dogs contain between 9-55 mg nitrate/kg fresh weights, up to a 300 fold reduction. Currently, the acceptable daily intake (ADI) by the World Health Organization is 0-3.7 mg nitrate/ $\mathrm{kg}$ body weight. In the United States, the daily allowable limit by the Environmental Protection Agency (EPA) is $7.0 \mathrm{mg}$ nitrate/kg body weight. This corresponds to 222 to $420 \mathrm{mg}$ /day for a $60 \mathrm{~kg}$ individual. For perspective, a single dose of beetroot juice may deliver over 200 mg. Similarly, a hypothetical calculation of an individual following the DASH dietary pattern with a focus for consumption of vegetables and fruits high in nitrate my reach $1200 \mathrm{mg}$ /day [7].

Beetroot juice has been involved in numerous scientific studies in the last several years, primarily involving aspects of its role in vascular health. Dietary nitrate found in our foods is taken up in the upper gastrointestinal tract and mixes in the blood with nitrate formed endogenously by dioxygenation of nitric oxide; nitrate has a plasma half-life of 5-6 hours. Up to $25 \%$ of plasma nitrate is taken up by salivary glands so that concentrations of nitrate in saliva can be 20 -fold higher than in plasma. Some of this nitrate is reduced to plasma nitrite by commensal oral bacteria. A portion of the nitrite formed ends up in the plasma, either being absorbed as nitrous acid or by first becoming NO and then being re-oxidized to nitrite. Importantly, this nitrate/nitrite cycle makes relatively long-term increases in plasma nitrite possible.
Ingesting high nitrate dietary sources leads to substantial increases in plasma nitrite. The nitrite is subsequently reduced to nitric oxide, and this conversion is enhanced in hypoxic conditions. In addition to the generation of nitric oxide by the reduction of nitrite, the primary mode of nitric oxide generation is through the oxidative pathway of Nitric Oxide Synthase (NOS) enzymes. A variety of isoforms of these exist in many different tissues in the body, and nitric oxide formation involves the conversion of arginine, NADPH and oxygen into nitric oxide and citrulline.

Nitric oxide is a well-known potent vasodilator; its formation and subsequent action is purported in to occur in conditions where poor vascular health is frequently seen. These include conditions such as diabetes, hypertension, cardiovascular disease, peripheral artery disease, cognitive impairment, and reduced cerebral blood flow, many of which are prominent with aging. Thus, including in our diet foods and supplements high in nitrate is being linked with improved health across a number of conditions. Furthermore, several studies have shown significant benefits in exercise performance in athletes. Taken together, there is a potentially enormous demand and tremendous economic market for beetroot juice. Again, this potential is realized in the number of companies hoping to cash in on these results.

As the supplement industry continues to jump-on the bandwagon with this concept, there will be some uneasiness based on the historical negative health implications observed with high nitrate consumption. Very high concentrations of nitrate in drinking water were thought to cause methemoglobinemia in infants, but more recent research has questioned whether nitrate or nitrite alone is the cause or if bacterial infection is also required [8,9]. In the 1970s, concern over the possibility of nitrite causing cancer arose from the theoretical association between the ability of nitrite to form nitrosamines in the gut and studies showing that nitrosamines are carcinogenic [9-12]. However, the evidence that high levels of dietary nitrate cause any type of cancer is weak and most studies have found no link between dietary nitrate and cancer at all $[9,10]$. This being said, it is possible that some human subpopulations may be especially sensitive to cancer causing effects of nitrate and continued monitoring of this potential untoward health effect is advisable. Due to the gradual reduction of nitrate to nitrite by oral bacteria following continual re-uptake of nitrate by salivary glands, nitrite levels in the gut or plasma never get extremely high with a high nitrate intake. Thus, consumption of nitrate vs. nitrite may provide greater safety for the consumer. After an extensive review of relevant literature, Milkowski et al. concluded that "the weak and inconclusive data on nitrite and nitrate cancer risks described here are far outweighed by the health benefits

*Corresponding author: Gary D. Miller, Department of Health and Exercise Science, Wake Forest University, Winston-Salem, NC 27109, USA, Tel: 336-7581901; E-mail: millergd@wfu.edu

Received October 23, 2013; Accepted October 24, 2013; Published October 28, 2013

Citation: Miller GD (2013) Beets Go Mainstream. J Nutr Disorders Ther 3: e113. doi:10.4172/2161-0509.1000e113

Copyright: ( 2013 Miller GD. This is an open-access article distributed under the terms of the Creative Commons Attribution License, which permits unrestricted use, distribution, and reproduction in any medium, provided the original author and source are credited. 
of restoring $\mathrm{NO}$ homeostasis as described by the volumes of published work over the past 10 years" [10].

So, is it time to promote and drink beetroot juice? Or are we better off eating our beets, as well as the spinach, kale, rucola, and other green leafy vegetables? These are just a few of the unanswered questions. We should be wary of the reductionist approach to science, but the evidence has been convincing that the health benefits of beetroot juice are attributed to the nitrate content, as placebos have been developed where only nitrate has been removed from the juice and there is no effect on the measured outcomes compared to the nitrate containing product.

\section{References}

1. Bhupathiraju SN, Wedick NM, Pan A, Manson JE, Rexrode KM, et al. (2013) Quantity and variety in fruit and vegetable intake and risk of coronary heart disease. Am J Clin Nutr.

2. Ruel G, Shi Z, Zhen S, Zuo H, Kroger E, et al. (2013) Association between nutrition and the evolution of multimorbidity: The importance of fruits and vegetables and whole grain products. Clin Nutr.

3. Hartley L, Igbinedion E, Holmes J, Flowers N, Thorogood M, et al. (2013) Increased consumption of fruit and vegetables for the primary prevention of cardiovascular diseases. Cochrane Database Syst Rev.

4. Sluik D, Boeing H, Li K, Kaaks R, Johnsen NF, et al. (2013) Lifestyle factors and mortality risk in individuals with diabetes mellitus: are the associations different from those in individuals without diabetes? Diabetologia.

5. Crane TE, Khulpateea BR, Alberts DS, Basen-Engquist K, Thomson CA (2013) Dietary Intake and Ovarian Cancer Risk: A Systematic Review. Cancer Epidemiol Biomarkers Prev.

6. Marchioli R, Schweiger C, Levantesi G, Tavazzi L, Valagussa F et al. (2001) Antioxidant vitamins and prevention of cardiovascular disease: epidemiological and clinical trial data. Lipids 36: S53-63.

7. Hord NG, Tang Y, Bryan NS (2009) Food sources of nitrates and nitrites: the physiologic context for potential health benefits. Am J Clin Nutr 90: 1-10.

8. Avery AA (1999) Infantile methemoglobinemia: reexamining the role of drinking water nitrates. Environ Health Perspect 107: 583-586.

9. Gilchrist M, Winyard PG, Benjamin N (2010) Dietary nitrate good or bad? Nitric Oxide 22: 104-109.

10. Milkowski A, Garg HK, Coughlin JR, Bryan NS (2010) Nutritional epidemiology in the context of nitric oxide biology: a risk-benefit evaluation for dietary nitrite and nitrate. Nitric Oxide 22: 110-119.

11. Tannenbaum SR, Weisman M, Fett D (1976) The effect of nitrate intake on nitrite formation in human saliva. Food Cosmet Toxicol 14: 549-552.

12. Spiegelhalder B, Eisenbrand G, Preussmann R (1976) Influence of dietary nitrate on nitrite content of human saliva: possible relevance to in vivo formation of N-nitroso compounds. Food Cosmet Toxicol 14: 545-548. 